\title{
RESEARCH
}

Open Access

\section{Effect of the native strain of the predator Nesidiocoris tenuis Reuter and the entomopathogenic fungi Beauveria bassiana and Lecanicillium muscarium against Bemisia tabaci (Genn.) under greenhouse conditions in Tunisia}

Besma Hamrouni Assadi ${ }^{1 *}$, Sabrine Chouikhi ${ }^{1}$, Refki Ettaib ${ }^{1}$, Naima Boughalleb M'hamdi ${ }^{2}$ and Mohamed Sadok Belkadhi ${ }^{1}$

\begin{abstract}
Background: The misuse of chemical insecticides has developed the phenomenon of habituation in the whitefly Bemisia tabaci (Gennadius) causing enormous economic losses under geothermal greenhouses in southern Tunisia.

Results: In order to develop means of biological control appropriate to the conditions of southern Tunisia, the efficacy of the native strain of the predator Nesidiocoris tenuis Reuter (Hemiptera: Miridae) and two entomopathogenic fungi (EPF) Beauveria bassiana and Lecanicillium muscarium was tested against Bemisia tabaci (Gennadius). Indeed, the introduction of $N$. tenuis in doses of 1, 2, 3, or 4 nymphs per tobacco plant infested by the whitefly led to highly significant reduction in the population of $B$. tabaci, than the control devoid of predator. The efficacy of $N$. tenuis was very high against nymphs and adults of B. tabaci at all doses per plant with a rate of $98 \%$. Likewise, B. bassiana and L. muscarium, compared to an untreated control, showed a very significant efficacy against larvae and adults of $B$. tabaci. In addition, the number of live nymphs of $N$. tenuis treated directly or introduced on nymphs of B. tabaci treated with the EPF remained relatively high, exceeding 24.8 nymphs per cage compared to the control (28.6).
\end{abstract}

Conclusions: It can be concluded that the native strain of $N$. tenuis and the EPF tested separately were effective against $B$. tabaci. Their combined use appears to be possible.

Keywords: Bemisia tabaci, Biological control, Nesidiocoris tenuis, Geothermal, Beauveria bassiana, Lecanicillium muscarium

\footnotetext{
*Correspondence: bessadi_27@yahoo.fr

${ }^{1}$ Dryland and Oases Cropping Laboratory, Arid Regions Institute, Street El

Jorf, 4119 Medenine, Tunisia

Full list of author information is available at the end of the article
}

Springer Open
๑) The Author(s). 2021 Open Access This article is licensed under a Creative Commons Attribution 4.0 International License, which permits use, sharing, adaptation, distribution and reproduction in any medium or format, as long as you give appropriate credit to the original author(s) and the source, provide a link to the Creative Commons licence, and indicate if changes were made. The images or other third party material in this article are included in the article's Creative Commons licence, unless indicated otherwise in a credit line to the material. If material is not included in the article's Creative Commons licence and your intended use is not permitted by statutory regulation or exceeds the permitted use, you will need to obtain permission directly from the copyright holder. To view a copy of this licence, visit http://creativecommons.org/licenses/by/4.0/. 


\section{Background}

Despite its importance, the geothermal greenhouse sector faces several phytosanitary constraints, including the whitefly Bemisia tabaci (Gennadius) (Hemiptera: Aleyrodidae) the devastator of several agricultural crops. This insect is one of the most destructive pests in the world (Oliveiraa et al., 2001). It transmits more than 200 plant viruses (Polston et al., 2014) and causes severe economic damage to more than 60 crop plants. In southern Tunisia, this whitefly causes harmful damage to crops heated by geothermal waters (Bel Kadhi, 2004).

Control of this pest has been based primarily on the use of conventional broad-spectrum chemical pesticides. As a result, B. tabaci developed resistance against different groups of insecticides following their intensive use (Sain et al., 2019). In addition to marketing problems, the use of chemicals in a heated greenhouse could pose poisoning problems for farmers (Bel Kadhi, 2004). The development of biological control methods is crucial, since the introduction of biological control agents in pest management programs provides a more stable results (Aggarwal et al., 2016). The use of as many natural enemies as possible in agricultural production systems can replace the use of pesticides (Trdan et al., 2020). Among other natural agent antagonists of the whitefly $B$. tabaci, Nesidiocoris tenuis Reuter (Hemiptera: Miridae) is a predatory zoophytophagous bug, naturally present in tomato crops in the Mediterranean basin (Perdikis and Arvaniti, 2016). It is used to control whiteflies (Hemiptera: Aleyrodidae), tomato leaf miner, and mites (Sanchez et al., 2014 and Yano et al., 2020). Similarly, the use of EPF is a relevant tool in biological control of whitefly (Faria and Wraightb, 2001). Some EPF, such as Beauveria spp., Metarhizium spp., Lecanicillum spp., and Isaria spp., were developed as mycoinsecticides (de Faria and Wraight, 2007). They are often used as an effective alternative for controlling insect pests throughout the world (de Faria and Wraight, 2007). In the quest for an integrated pest management program, based on the use of biological control agents, appropriate to the conditions of geothermal greenhouse, in southern Tunisia and meeting the "Global Gap" standards that govern the export niche, this study evaluated the efficacy of the two EPF B. bassiana and L. muscarium and the native predatory bug $N$. tenuis. In addition, the effect of these fungi on the survival of the predator was studied.

\section{Methods}

Insect

$B$. tabaci and the native predator $N$. tenuis were collected from oases in southern Tunisia. The predator and the pest were reared on a tomato crop in the same greenhouse of $9 \times 30 \mathrm{~m}$ managed in organic mode, located at the Technical Center for Protected and
Geothermal Crops in Chenchou Tunisia-Gabès (TCPG)

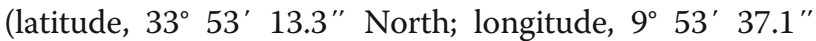
East; elevation $78 \mathrm{~m}$ ). The insects were reared for 2 years from March 2016 until March 2018. The whiteflies collected from the biological greenhouse using a manual aspirator were introduced into previously prepared tobacco plants in pots in a glasshouse. Three weeks later, the mirid bug was collected from TCPG's greenhouse and subsequently released on plants infested with $B$. tabaci.

\section{Preparation of entomopathogenic fungi}

Two biological formulations based on EPF were tested on $B$. tabaci under controlled conditions. One was based on Lecanicillium muscarium strain Ve6 (19-79) with a water-soluble granular formulation of $10^{10}$ spores/g, and the other was based on Beauveria bassiana strain R 444 in wettable powder with a concentration of $2 \times 10^{9}$ conidia/g.

\section{Experimental method \\ Effect of N. tenuis on B. tabaci}

The study of the efficacy of 5 doses of treatment with $N$. tenuis nymphs was carried out on Nicotiana tabacum plants, previously prepared in pots and installed in cages in a glasshouse, under controlled conditions, at a temperature of $27 \pm 1^{\circ} \mathrm{C}$ and $\mathrm{RH}$ of $75 \pm 5 \%$.

Fifteen wooden cages measuring $1 \times 1 \times 1.2 \mathrm{~m}$, covered on all three sides with an insect proof canvas (20/ 10 threads $/ \mathrm{cm}$ ), were prepared and installed in a glasshouse compartment. Each cage containing 5 tobacco plants was assigned to one of the 5 doses of $0,1,2,3,4$, and $5 \mathrm{~N}$. tenuis nymphs per plant. All 3 cages correspond to one treatment, and the whole was arranged in a randomized complete block design. At the 6-7 leaf stage, the plants in each cage were infested by adults of B. tabaci. A week after the infestation, control of the population level of $B$. tabaci began. When the pest population reached 9 individuals/leaf, inoculation by $N$. tenuis nymphs was carried out. A week later, until the 14th week, monitoring of the population level of nymphs and adults of B. tabaci was carried out (Calvo et al., 2009). Using a hand-held magnifying glass, an on-site analysis of a randomly selected leaf on each plant allowed the number of adults and larvae of B. tabaci and $N$. tenuis to be counted. Counting was done early in the morning and turning the leaves gently to avoid disturbance of mirid bug and whitefly adults.

The follow-up of the test was stopped at week 14, when it was noted that the vegetative state of the plants no longer allows the normal development of the whitefly due to lack of food, which can distort the efficacy of $N$. tenuis. 


\section{Efficacy of B. bassiana and L. muscarium on B. tabaci}

The pathogenicity of $B$. bassiana and $L$. muscarrium was tested against the population of B. tabaci on Cucumis sativus, "Vigorex variety". To do this, cucumber plants were transplanted into 2-1 plastic pots, filled with organic peat, and fertilized with a standard nutrient solution. Twelve wooden cages measuring $1 \times 1 \times 1.2 \mathrm{~m}$, covered on all three sides with an insect proof canvas (20/10 threads/cm), were prepared and installed in a glasshouse compartment. In each cage, 5 cucumber plants were introduced. Four treatments were evaluated: 1 (1 g B. bassiana +11 sterile distilled water $+0.1 \%$ Tween 80); 2 (1 g L. muscarium + 1 l sterile distilled water $+0.1 \%$ Tween 80$) ; 3$ (0.5 g of B. bassiana $+0.5 \mathrm{~g}$ of L. muscarium +1 l sterile distilled water $+0.1 \%$ Tween 80); 4 ( 1 l sterile distilled water $+0.1 \%$ Tween 80). Therefore, all the 3 cages correspond to a treatment, and the whole was arranged in a randomized complete block design.

The infestation of cucumber plants with B. tabaci was previously accomplished. When plants reached stages 5 to 6 leaves, B. tabaci adults were introduced to tobacco plants at the rate of 50 adults per leaf. Three weeks later, when the different stages of $B$. tabaci were present, the plants were treated with a sprayer of 11 volume until runoff. Each cage was treated with $0.4 \mathrm{l}$ of the suitable preparation of the EPF. During the trial, these treatments were repeated 3 times with 10-day intervals.

To avoid any risk of contamination of the plants of a well-defined cage by the products intended for the plants of the neighboring cages, during the treatments, the cages of the plants not concerned were protected by plastic sheeting. Seven days later, the assessment began with a random weekly sampling by collecting 15 leaves per treatment at a rate of one leaf per plant.

Four sampling spaced 7 days intervals were conducted. Immediately after collection, the leaves were examined in the laboratory under binocular loupe to count the number of individuals of the different stages by identifying the dead individual. Nymph mortality was either a whitish or reddish color depending on the strain of the fungus in question, or a mycelial development on the cadavers (Quesada-Moraga et al., 2006).

\section{Effects of EPF on the survival of $N$. tenuis nymphs}

At this level, tomato plants (Solanum lycopersicum) were previously infested with adults of $B$. tabaci. Trials began when the B. tabaci population reached 30-40 nymphs per leaf. To study the effect of EPF on the survival of $N$. tenuis nymphs, the same treatments used in the fungus pathogenicity study were tested but in two different cases. In the first step, to test the effect of direct spraying of fungi on the survival of $N$. tenuis, the predator was introduced at the rate of 3 individuals per plant infested with B. tabaci. Twenty-four hours later, the plants were treated by the fungi. For each treatment, 10 plants were protected by a cage, replicated by 5 . The whole was arranged in a randomized complete block design. Each cage was treated by 0.81 using a 1-1 sprayer. In the second step, to evaluate the effect of fungi already installed on a nymphal population of B. tabaci on the survival of $N$. tenuis nymphs, whitefly infested plants were treated by different EPF. Nymphs of $N$. tenuis, at a rate of 3 individuals per plant, were introduced at different times after treatment by fungi. Thus, the first lot was brought after $1 \mathrm{~h}$, the second after $24 \mathrm{~h}$, the third after 3 days, the fourth after 5 days, and the fifth after 7 days. This controlled test was repeated 5 times in succession. In all trials, counting of live $N$. tenuis nymphs was performed 3 days after their introduction. The experiments were conducted in separate compartments of the glasshouse.

\section{Statistical analyses}

For variance analysis (ANOVA), nymphal and adult populations of the whitefly and nymphs of $N$. tenuis, efficacy rates of $N$. tenuis against $B$. tabaci, and number of live predator nymphs were subjected to unidirectional analysis associated with a Tukey HSD test $(p<0.05)$ using the XLSTAT 2019 software, Microsoft Excel. Reduction of $B$. tabaci by the predator and treated pathogens verified according to the Henderson and Tilton formula was calculated (Henderson and Tilton, 1955).

Reduction $(\%)=(1-($ No. in control before treatment $\times$ No. in treatment after treatment)/(No. in control after treatment $\times$ No. in treatment before treatment) $)^{*} 100$.

\section{Results}

\section{Effect of $N$. tenuis on B. tabaci}

\section{Evolution of B. tabaci according to treatments}

In the absence of $N$. tenuis, the level of the larval population of B. tabaci progressed gradually until the end of the test, recording a maximum of $612.00 \pm 68.48$ nymphs per leaf at the 14th week (Fig. 1a). On the other hand, after treatment with nymphs of the $N$. tenuis bug, the numbers of nymphs of the whiteflies decreased significantly depending on the inoculation dose. Indeed, at the end of the test, there were numbers of nymphal populations of the whitefly of $360.40 \pm 34.78,299.06 \pm$ $12.07,93.13 \pm 7.51$, and $33.13 \pm 7$ individuals with an efficacy rate, respectively, of 98.60, 98.50, 98.44, and $98.80 \%$ for $1,2,3$, and $4 N$. tenuis nymphs per plant (Table 1). Thus, the analysis of the variance of the mean numbers of larvae of $B$. tabaci showed highly significant difference among the effect of the different doses of treatment by $N$. tenuis $(p<0.0001)$.

As for the adult population of B. tabaci, at the end of the test, the maximum number of individuals per leaf at the control level (no N. tenuis) is $97.73 \pm 7.28$ (Fig. 1b). 

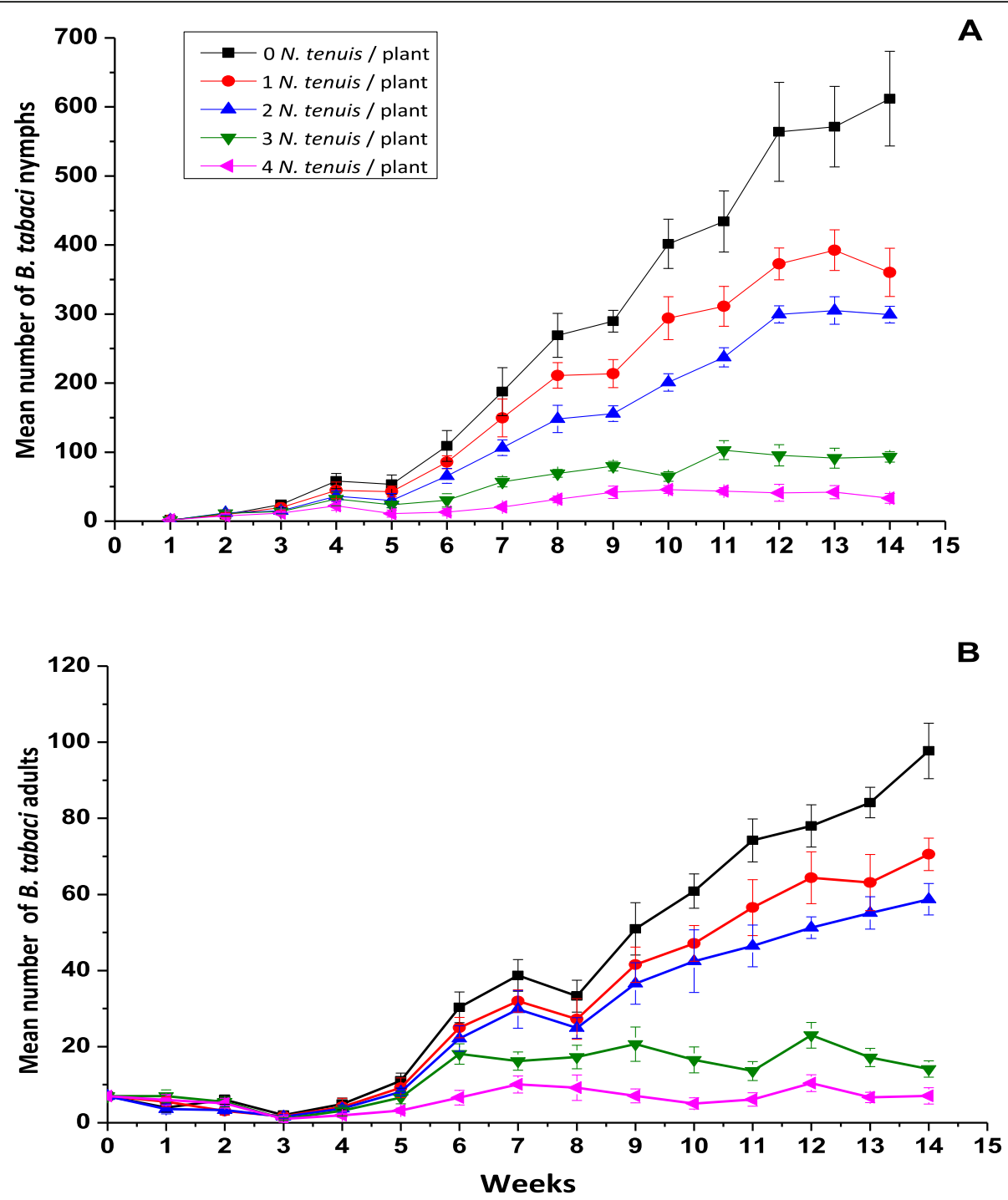

Fig. 1 Mean $( \pm S D)$ number of Bemisia tabaci nymphs and adults as a function of treatment concentrations with $(0,1,2,3$, and 4$)$ Nesidiocoris tenuis nymphs per plant for 14 weeks (a nymph population, $\mathbf{b}$ adult population)

On the other hand, treatment of the B. tabaci population with different doses of $N$. tenuis showed a significant decrease in the adult population because of an increase in the number of introduced predator nymphs. The numbers of adults per leaf were $70.53 \pm 4.27,58.73$ $\pm 4.11,14.13 \pm 2.16$, and $7.06 \pm 2.12(p<0.0001)$, respectively, for treatment doses per plant of $1,2,3$, and 4 nymphs. The efficacy rates of $N$. tenuis against adults of B. tabaci are $98.25,98.33,98.71$, and $98.34 \%$ for treatment doses per plant of $1,2,3$, and 4 nymphs, respectively (Table 1).

Analysis of the whitefly population level at the end of the 1st week for the control showed a low number of first-instar nymph of about two nymphs per leaf. This period of about 7 days was the time required for the incubation of the eggs and the appearance of the first- stage nymphs. The nymphal population, all stages combined, began to increase from the 2nd week onwards in a remarkable way reaching 9 nymphs per leaf. Thus, at the end of the 2nd week, the starting point of the $N$. tenuis nymph treatment trial, all fertile eggs resulted in a large nymphal population, formed by the different nymphal instars. At the end of the 3rd week, the adult population became small and showed a marked change after this period. This coincided with the emergence of first-generation adults and the disappearance of adults introduced about 21 days ago. A further decline in adult numbers was recorded at week 8 , followed by a gradual increase in nymphs and adults expressing the staggered development of new generations.

After establishment of the predator, the number of larvae and adults of $B$. tabaci decreased with the number 
Table 1 Efficacy rate of Nesidiocoris tenuis against Bemisia tabaci nymphs and adults as a function of treatment and time

\begin{tabular}{|c|c|c|c|c|c|c|c|c|}
\hline \multirow[b]{2}{*}{ Weeks } & \multicolumn{4}{|c|}{ Nymphs } & \multicolumn{4}{|l|}{ Adult } \\
\hline & $1 \mathrm{~N} / \mathrm{PL}$ & $2 \mathrm{~N} / \mathrm{PL}$ & $3 \mathrm{~N} / \mathrm{PL}$ & $4 \mathrm{~N} / \mathrm{PL}$ & $1 \mathrm{~N} / \mathrm{PL}$ & $2 \mathrm{~N} / \mathrm{PL}$ & $3 \mathrm{~N} / \mathrm{PL}$ & $4 \mathrm{~N} / \mathrm{PL}$ \\
\hline 3 & 19.36 & 51.71 & 51.94 & 87.17 & 43.48 & 52.00 & 81.71 & 80.52 \\
\hline 4 & 63.56 & 61.47 & 63.04 & 70.09 & 26.04 & 27.64 & 2.82 & 40.04 \\
\hline 5 & 83.13 & 85.48 & 87.00 & 91.29 & 69.23 & 70.00 & 70.88 & 77.12 \\
\hline 6 & 82.95 & 81.30 & 89.21 & 89.74 & 86.29 & 86.22 & 86.19 & 89.60 \\
\hline 7 & 91.29 & 91.94 & 90.60 & 92.31 & 94.94 & 94.68 & 96.46 & 93.98 \\
\hline 8 & 95.11 & 95.17 & 95.80 & 94.62 & 96.08 & 96.15 & 95.10 & 95.80 \\
\hline 9 & 96.74 & 96.61 & 96.29 & 95.73 & 95.42 & 95.59 & 96.40 & 97.69 \\
\hline 10 & 96.80 & 97.00 & 98.11 & 97.46 & 97.15 & 97.08 & 97.99 & 98.20 \\
\hline 11 & 97.72 & 97.46 & 96.58 & 97.96 & 97.53 & 97.74 & 98.30 & 97.50 \\
\hline 12 & 98.02 & 97.91 & 98.46 & 98.44 & 97.77 & 97.84 & 96.68 & 96.67 \\
\hline 13 & 98.28 & 98.34 & 98.44 & 98.33 & 98.22 & 98.04 & 98.65 & 98.83 \\
\hline 14 & 98.60 & 98.50 & 98.44 & 98.80 & 98.25 & 98.33 & 98.71 & 98.34 \\
\hline
\end{tabular}

N/PL number of Nesidiocoris tenuis per plant

of introduced $N$. tenuis nymphs (Fig. 1). For treatment doses of one and two $N$. tenuis per plant, the whitefly population followed the same pattern as the control population up to the 12th week. Thereafter, the number of nymphs decreased from the 12th week for the dose of 2 nymphs and from the 13th for the dose of one nymph of $N$. tenuis per plant. While for 3 and $4 N$. tenuis nymphs per plant, changes in larval and adult populations remained relatively low compared to the control.

\section{Evolution of $N$. tenuis population according to treatments}

Once settled on the whitefly larval population, the level of the $N$. tenuis population changed according to their number of leaves starting at the level of each leaf following an exponential function (Fig. 2). The analysis of the variance of the means of the populations of the predator $N$. tenuis associated with the population of B. tabaci showed that there was a highly significant difference among the populations of the different doses of treatments $(p<0.0001)$. For high doses of 3 and 4 nymphs per plant, at week 14, N. tenuis exceeded 2 individuals per leaf: 2.06 and 2.4 individuals, respectively. While for the doses of 1 and 2 nymphs, the number remained relatively low, not exceeding 0.6 individuals per leaf were respectively 0.53 and 0.66 individuals per leaf. The whitefly nymphal population at doses 1 and 2 did not decline until the 13th week in which $N$. tenuis began to control the pest population (Fig. 2). However, with the same treatment doses, the number of adults of $B$. tabaci remained in increasing evolution. The exponential

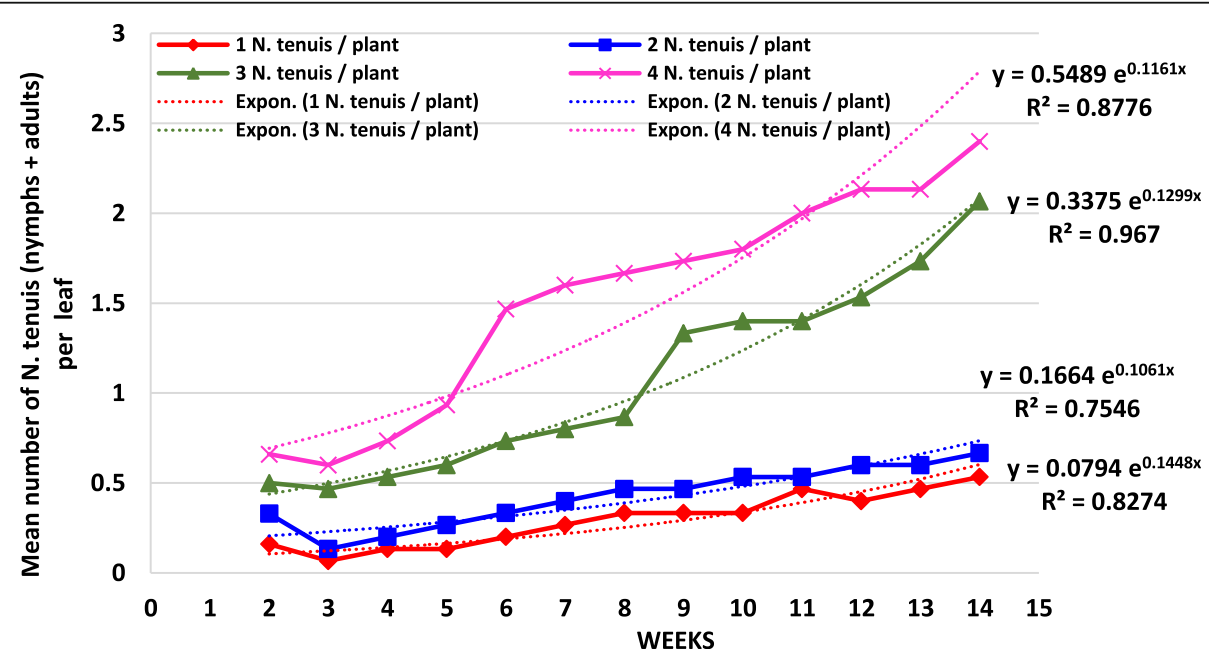

Fig. 2 Mean number of Nesidiocoris tenuis (nymphs + adults) per leaf and exponential analysis of the mean as a function of treatment concentrations with $(1,2,3$, and 4) predator nymphs per plant for 14 weeks 
functions for doses $1,2,3$, and 4 nymphs per leaf were respectively $y=0.0794 \mathrm{e}^{0.1448 \mathrm{x}}, y=0.1664 \mathrm{e}^{0.1061 \mathrm{x}}, y=$ $0.3375 \mathrm{e}^{0.1299 \mathrm{x}}$, and $y=0.5489 \mathrm{e}^{0.1161 \mathrm{x}}$.

\section{Analysis of correlations between the various factors}

Positive linear relationships were established between the efficacy rates of $N$. tenuis against whitefly larval population and the population density of the mirid bug at each treatment dose (Table 2). To estimate the density needed to control the entire whitefly population, equations corresponding to the different doses used were developed. These equations for doses 1, 2, 3, and 4 nymphs per leaf are $\mathrm{Y} 1=43.43 \mathrm{X} 1+87.80, \mathrm{Y} 1=83.13$ $\mathrm{X} 1+51.71, \mathrm{Y} 1=7.78 \mathrm{X} 1+85.18$, and $\mathrm{Y} 1=6.92 \mathrm{X} 1+$ 83.09 , respectively. The calculation of the density required to eradicate the entire whitefly population was respectively $0.28,0.58,1.9$, and 2.44 individuals per leaf for $1,2,3$, and 4 nymphs of $N$. tenuis per plant. To estimate the time required to reach the density of $N$. tenuis that allowed control of the entire whitefly population, positive linear relationships between the efficacy rates of $N$. tenuis against whitefly larval population and the time were developed. Equations corresponding to the different doses used were established (Table 2).

These equations for doses $1,2,3$, and 4 nymphs per leaf were $\mathrm{Y} 2=0.8543 \mathrm{X} 2+87.6, \mathrm{Y} 2=0.7875 \mathrm{X} 2+$ $88.348, \mathrm{Y} 2=0.8702 \mathrm{X} 2+87.454$, and $\mathrm{Y} 2=0.8638 \mathrm{X} 2+$ 87.636, respectively. Of course, the time required to eliminate the entire population was closely related to the dose used at the start of treatment.

\section{Efficacy of B. bassiana and L. muscarrium on B. tabaci}

The successive treatments against $B$. tabaci by the EPF, $B$. bassiana and L. muscarium, demonstrated the efficacy of the different treatments against the developmental stages of $B$. tabaci. Indeed, the variance analysis of efficacy rates showed a significant difference between treatments (Fig. 3).
In the case of the 1st instar (L1) nymphs, the analysis of the variance of efficacy rates revealed that the effect of association of the 2 fungi was similar to that caused by $B$. bassiana alone over time, except for the 1 st of follow-up, where the former was the most effective. In fact, efficacy rates from both fungi ranged from 64.97 to $77.05 \%$, followed by efficacy rates from $B$. bassiana ranging from 44.22 to $72.86 \%$, followed by efficacy rates from L. muscarium ranging from 38.58 to $61.04 \%$ ( $p<$ 0.0001 , Fig. 3a). For the 2nd instar L2, variance analysis showed that mixing of the 2 fungi was most effective over time with efficacy rates ranging from 77.65 to 95.02\%. B. bassiana and L. muscarium had a comparable effect ( $p<0.0001$, Fig. 3b).

For the 3rd nymphal instar (L3), variance analysis showed that the 2 associated fungi were most effective over time, except that in the 4th week of treatment, both fungi and $B$. bassiana had a similar effect. The efficacy rates ranged from 73.15 to $84.97 \%$ ( $p<0.0001$, Fig. 3c). As for the 4th instar L4, the analysis of the variance showed that the 2 associated fungi were the most effective over time, except that in the 3rd week of treatment, both fungi and $B$. bassiana had a similar effect $(p<$ 0.0001 , Fig. 3d). In the case of pupae, the analysis of variance showed that treatment by fungi had the same effect as that on 4th instar L4 ( $p<0.0001$, Fig. 3e). For the adult stage, variance analysis of efficacy rates showed that the mixture of the 2 fungi was the most effective with the rates varying between 49.63 and $61.05 \%$. B. bassiana and L. muscarium had a comparable effect over time, except in the 4th week of treatment $(p<0.0001$, Fig. 3f). It can be concluded that the 2nd nymphal instar of development revealed the highest sensitivity to different treatments, with efficacy rates reaching $95.02 \%$ at the 4th week of treatment. However, the pupal stage was the most resistant to different treatments resulting in low efficacy rates not exceeding $61.05 \%$.

Table 2 Densities of Nesidiocoris tenuis nymphs and periods needed to control the entire population of Bemisia tabaci according to doses

\begin{tabular}{|c|c|c|c|c|c|}
\hline & & $\begin{array}{l}1 \mathrm{~N} . \text { tenuis } \\
\text { per plant }\end{array}$ & $\begin{array}{l}2 N . \text { tenuis } \\
\text { per plant }\end{array}$ & $\begin{array}{l}3 N . \text { tenuis } \\
\text { per plant }\end{array}$ & $\begin{array}{l}4 \mathrm{~N} . \text { tenuis } \\
\text { per plant }\end{array}$ \\
\hline \multirow[t]{3}{*}{$\begin{array}{c}\text { Efficacy of } N \text {. tenuis against } B \text {. tabaci } \\
\text { nymphs }\end{array}$} & Linear equation & $\begin{array}{l}Y 1=43.43 \times 1 \\
+87.80\end{array}$ & $\begin{array}{l}Y 1=83.13 \times 1 \\
+51.71\end{array}$ & $\begin{array}{l}Y 1=7.78 \times 1+ \\
85.18\end{array}$ & $\begin{array}{l}Y 1=6.92 X 1 \\
+83.09\end{array}$ \\
\hline & Coefficient of determination & $R^{2}=0.7947$ & $R^{2}=0.8083$ & $R^{2}=0.7524$ & $R^{2}=0.7459$ \\
\hline & $\begin{array}{l}\text { Density of } N \text {. tenuis reduces } 100 \% \text { of } \\
\text { nymphs }\end{array}$ & 0.28 & 0.58 & 1.9 & 2.44 \\
\hline \multirow[t]{3}{*}{$\begin{array}{l}\text { Efficacy of } N \text {. tenuis against } B \text {. tabaci } \\
\text { nymphs as a function of time }\end{array}$} & Linear equation & $\begin{array}{l}Y 2=0.8543 \\
X 2+87.6\end{array}$ & $\begin{array}{l}Y 2=0.7875 \\
X 2+88.348\end{array}$ & $\begin{array}{l}Y 2=0.8702 \\
X 2+87.454\end{array}$ & $\begin{array}{l}Y 2=0.8638 \\
X 2+87.636\end{array}$ \\
\hline & Coefficient of determination & $R^{2}=0.756$ & $R^{2}=0.7885$ & $R^{2}=0.6455$ & $R^{2}=0.853$ \\
\hline & $\begin{array}{l}\text { Time required to reduce the } B \text {. tabaci } \\
\text { population by } 100 \% \text { (Weeks) }\end{array}$ & 14.51 & 14.79 & 14.41 & 14.31 \\
\hline
\end{tabular}

$X 1, X 2$, reduction of Bemisia tabaci; $Y 1$, the population density of Nesidiocoris tenuis per leaf; $Y 2$, time (week) 

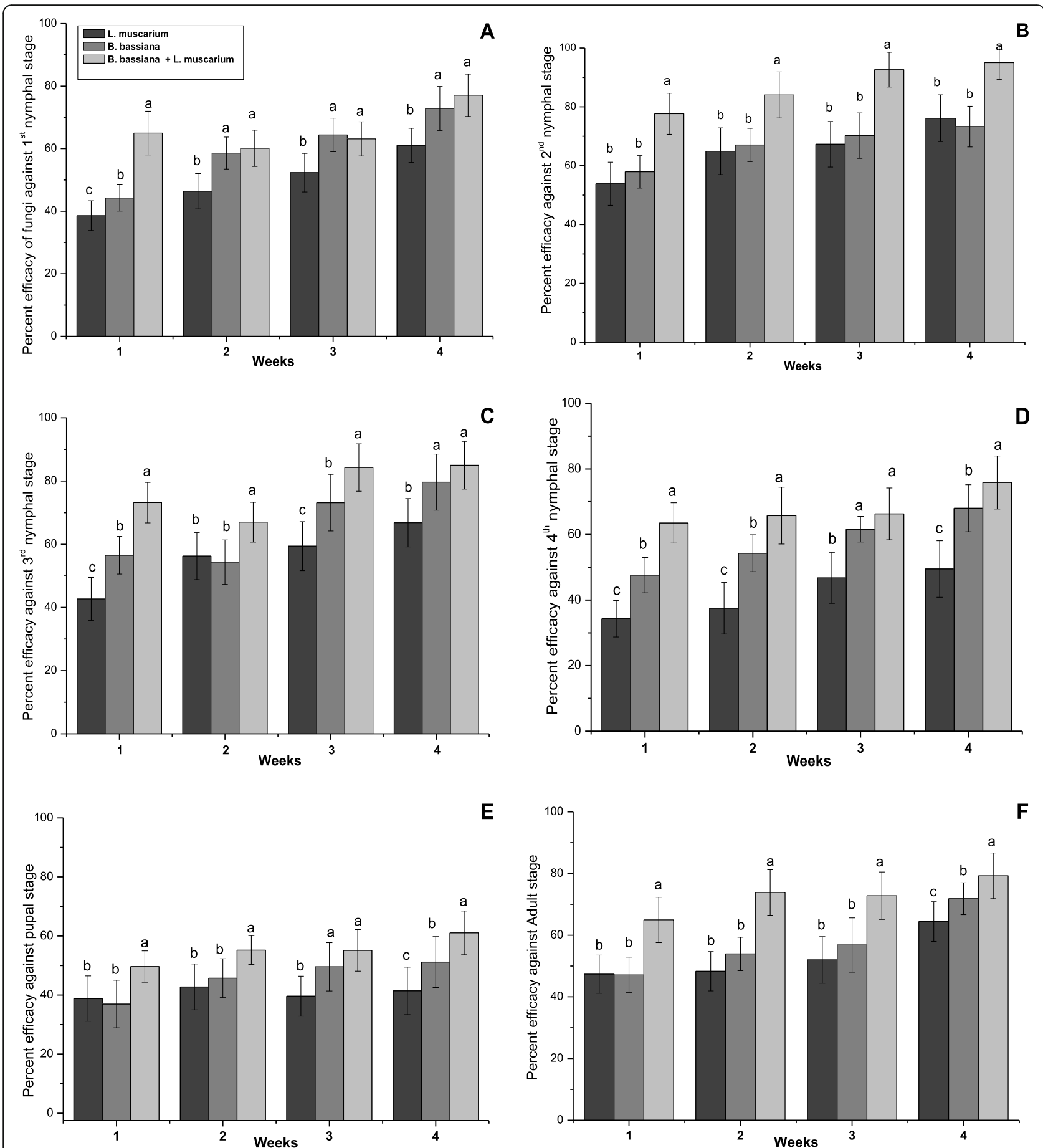

E

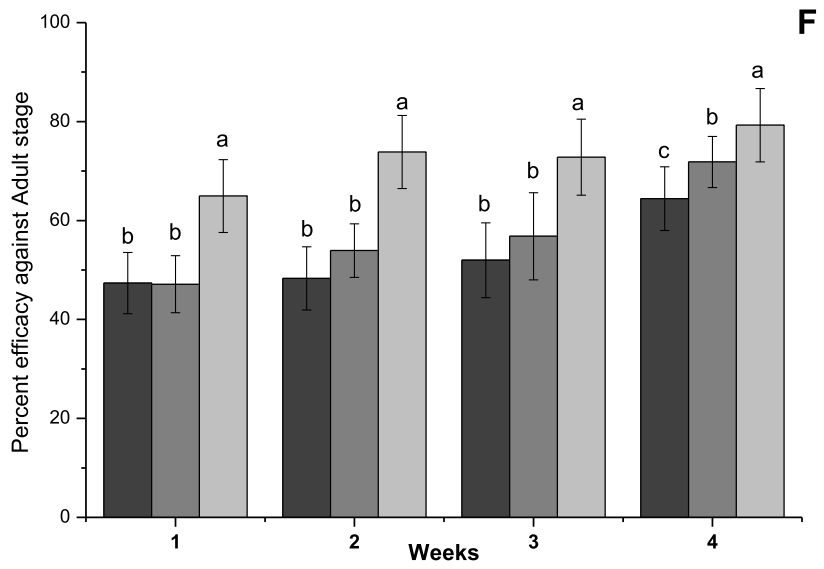

Fig. 3 Mean $( \pm S D)$ efficacy of entomopathogenic fungi against different stages of development of Bemisia tabaci for 4 weeks. Different letters denote means are significantly different from one another, as determined by Tukey's HSD. a 1st nymphal instar L1; b 2nd instar L2; c 3rd instar L3; d 4th instar L4; e pupa, and $\mathbf{f}$ adult

Effects of EPF on the survival of $N$. tenuis nymphs In the first step, a trial to elucidate the possible relationship between the EPF and the predatory insect, the most frequently used, has been performed. Direct treatment of $N$. tenuis nymphs, already associated with $B$. tabaci nymphs, by EPF, affected their survival. There was a statistically significant difference $(p<0.0001)$ (Table 3$)$ between the number of living predator nymphs per cage 
Table 3 Mean number of live nymphs of Nesidiocoris tenuis $( \pm S D)$ treated with entomopathogenic fungi

\begin{tabular}{|c|c|c|c|c|c|c|}
\hline \multirow[t]{2}{*}{ Treatments } & \multirow[b]{2}{*}{$\begin{array}{l}\text { Number of } \\
\text { live } \\
\text { nymphs of } \\
N . \text { tenuis } \\
\text { treated } \\
\text { directly } \\
\text { with fungi }\end{array}$} & \multicolumn{5}{|c|}{ Number of live nymphs of $N$. tenuis introduced on $B$. tabaci contaminated with fungi } \\
\hline & & 1 HAT & 1 DAT & 3 DAT & 5 DAT & 7 DAT \\
\hline Control & $28.6 \pm 0.28 \mathrm{a}$ & $29 \pm 0.7 \mathrm{a}$ & $29.2 \pm 0.83 a$ & $29 \pm 0 \mathrm{a}$ & $29.2 \pm 0.44 a$ & $29.2 \pm 0.83 a$ \\
\hline Lecanicillium muscarium & $25.2 \pm 1.27 b$ & $27.6 \pm 1.14 a b$ & $28.6 \pm 0.54 \mathrm{a}$ & $28.8 \pm 0.83 a$ & $26.4 \pm 1.14 b$ & $26 \pm 1.87 b$ \\
\hline Beauveria bassiana & $25.2 \pm 0.56 b$ & $26.8 \pm 0.83 b$ & $28.6 \pm 0.54 a$ & $28.6 \pm 0.89 a$ & $26 \pm 0.7 b$ & $26.2 \pm 1.48 b$ \\
\hline B. bassiana + L. muscarium & $24.8 \pm 0.14 b$ & $26.6 \pm 0.89 b$ & $28 \pm 1.22 \mathrm{a}$ & $28.2 \pm 0.83 a$ & $25.6 \pm 0.54 b$ & $25.8 \pm 1.92 b$ \\
\hline$F$ & 16.188 & 7.192 & 1.714 & 1.061 & 23.188 & 5.122 \\
\hline$P$ value & $<0.0001$ & 0.003 & 0.204 & 0.393 & $<0.0001$ & 0.011 \\
\hline
\end{tabular}

Different letters denote means are significantly different from one another, as determined by Tukey's HSD. HAT hour after treatment, DAT day after treatment

treated and untreated. However, the number of live nymphs remained high, over 24.8 nymphs per cage compared to the control, which was 28.6 .

On the other hand, the introduction of $N$. tenuis nymphs into a population of $B$. tabaci previously contaminated by the strains of the fungi $B$. bassiana and $L$. muscarium led to a variation in the number of living nymphs depending on the duration of exposure after treatment. Indeed, the analysis of the variance of the means of the numbers of live nymphs of $N$. tenuis showed a significant difference only between the numbers of live nymphs of the mirid bug after $1 \mathrm{~h}$ of exposure $(p=0.003), 5$ days $(p<0.0001), 7$ days of exposure ( $p$ $<0.0001$ ), and the untreated control. As for the numbers of live nymphs corresponding to 1 day and 3 days after contamination of the prey, the difference was not significant compared to the control.

\section{Discussion}

The efficacy study of the predator $N$. tenuis showed that the numbers of whitefly nymphs decreased remarkably depending on the inoculation dose. Concerning the monitoring of the evolution of nymphal and adult populations of the whitefly on tobacco in the absence of $N$. tenuis showed that the appearance of the 1st nymphal instar L1 requires about 7 days, and the lifespan of newly emerged introduced adults was almost equal to 21 days. These results were consistent with studies (Bel Kadhi, 2004), which showed that the development time of $B$. tabaci's eggs varies between 4 and 6 days, and that of 1st nymphal instar was an average of 2 days and a preoviposition near zero under controlled conditions similar to that of this test.

As for the evolution of the population of B. tabaci, after the introduction of $N$. tenuis, it showed a significant decrease in nymphs and adults for the different doses of treatment by $1,2,3$, or 4 mirid bug per plant compared to an untreated control under controlled conditions. These results are consistent with studies showing that $N$. tenuis was capable of controlling tobacco whitefly (Calvo et al., 2009). Similarly, the introduction of $N$. tenuis into the tomato greenhouse, from planting, could control populations of tobacco whitefly or Tuta absoluta (Calvo et al., 2012).

The efficacy rates of $N$. tenuis against nymphs and adults of whitefly were very high and reached $98 \%$ for all treatment doses at the end of the test. Likewise, Calvo et al. (2009) showed that $N$. tenuis treatment doses of 1 and 4 individuals per tomato plant had the same effect on the reduction of the population of $B$. tabaci with reduction of around $80 \%$. Also, the specificity of the host plant and the diet could influence the survival time of $N$. tenuis (Urbaneja et al., 2005). A study carried out in a geothermal greenhouse showed that $N$. tenuis had a preference for tobacco over tomatoes and melons (Ben Belgacem et al., 2016).

However, in this trial, all doses could not control the whitefly population, which remained large at the end of the trial. This may be due to the evolution of the predator, which was slow for different doses over time and reached only 2.4 individuals per leaf for the best dose of treatment. In fact, its low fertility of 60 nymphs per female was very low compared to that of $B$. tabaci, which was 130 (Sanchez et al., 2009). In addition, the developmental time of the predator's larvae was 21.8 days (Sanchez et al., 2009) longer than that of the 17-day pest (Bel Kadhi, 2004). These differences in the biological parameters of the 2 insects certainly influenced the control power of the B. tabaci population in a very limited period. In addition, treatment initiation with $N$. tenuis nymphs coincided with a high level of the whitefly larval population assessed at 9 larvae per leaf.

In this trial, at best, the whitefly population was completely controlled after 14.31 weeks, with the highest dose used being 4 nymphs per plant. Based on the preestablished equations, the periods necessary for the total 
elimination of whitefly populations were 14.51, 14.79, and 14.41 weeks for doses 1,2 , and 3, respectively. Thus, in the second step, it was able to determine the intervention period and the dose necessary to eliminate or even avoid the installation of a population of whiteflies.

In addition, the results of the trials undertaken to determine the level of pathogenicity of EPF B. bassiana and $L$. muscarium against B. tabaci associated with heated greenhouse crops in southern Tunisia were very interesting. In fact, the strains of B. bassiana and L. muscarium, used either separately or in a mixture, allowed to reduce the levels of the populations of the different development stages of $B$. tabaci. These results were in perfect agreement with that of several research studies that showed that EPF were effective at different stages of development of the whitefly (Quesada-Moraga et al., 2006; Park and Kim, 2010 and Polanczyk et al., 2019). The JAB07 isolates of B. bassiana and LCMAP3790 of $L$. muscarium resulted in more than $80 \%$ mortality of eggs and the 3rd instar nymphs of B. tabaci biotype B (Polanczyk et al., 2019). Similarly, B. bassiana strain Bb202 caused a good pathogenicity for B. tabaci above 77\% mortality (Ghulam et al., 2018).

In this study, B. bassiana was more effective than $L$. muscarium against all developmental stages of $B$. tabaci. This is consistent with the study of Mascarin et al. (2013), which showed that B. bassiana strain CG1229 was significantly more virulent to nymphs than all $L$. muscarium isolates, resulting in larval mortality rates greater than $71 \%$. Similarly, the in vitro study of Keerio et al. (2020) showed the efficacy of 2 strains of B. bassiana and one strain of L. lecanii against B. tabaci. L. lecanii resulted in lower mortality rate than the two strains of $B$. bassiana. In contrast, the commercial isolate of $L$. muscarium tested against the different stages of development of B. tabaci on poinsettia showed low efficacy (20$40 \%$ mortality) (Cuthbertson et al., 2008). This can be explained by the influence of factors, other than isolate, on the efficacy of fungi, such as application method, environmental conditions, or morphology.

The results showed a high sensitivity of the 2nd and 3rd nymphal B. tabaci instars to the fungi tested. Similarly, the mortality of the 2nd instar B. tabaci nymphs was the highest following application of $L$. muscarium under controlled laboratory and greenhouse conditions (Cuthbertson and Walters, 2005).

In addition, a study (Poprawski et al., 2000) found that the 3rd nymphal instar of Trialeurodes vaporariorum was the most sensitive to $B$. bassiana. According to Malekan et al. (2015) the 3rd and 4th nymphal instars of $B$. tabaci were more sensitive to B. bassiana and L. muscarium than the 1st and 2nd nymphal instars with mortality percentages of 63.74 and $62.49 \%$ on young nymphs and 71.68 and $87.13 \%$ on old nymphs, respectively.
The study of the effect of the 2 fungi $L$. muscarium and B. bassiana on the survival of $N$. tenuis showed that the number of nymphs significantly reduced than the control, when they were sprayed directly by the fungi or introduced on B. tabaci nymphs treated for $1 \mathrm{~h}$ or 5 or 7 days.

The number of live nymphs of $N$. tenuis introduced after $1 \mathrm{~h}$ of treatment of the nymphs of $B$. tabaci by $B$. bassiana and L. muscarium was lower than that of the control. This may be due to the direct contact of N. tenuis nymphs with the fungal preparation. Likewise, the survival of $N$. tenuis was affected after 5 and 7 days of treatment when the fungi developed in the nymphs of $B$. tabaci and the mortality of the latter increased. However, the number of live nymphs remained relatively high, over 24.8 nymphs per cage than the control, which was 28.6 nymphs.

\section{Conclusion}

It can be inferred from the results that the native predator $N$. tenuis alone reduced the population of B. tabaci, and its introduction well before the appearance of the pest increased its effectiveness. Similarly, microbiological control of the same pest with B. bassiana and L. muscurium significantly reduced the populations of $B$. tabaci. The effect of EPF used in association with a nymphal population of $N$. tenuis on nymphs' survival was low. Thus, the use of these biological means in combination, as part of an integrated pest control program, is recommended taking into account the time interval necessary between the introduction of $N$. tenuis and the treatment with EPF.

\section{Abbreviations}

TCPG: The Technical Center for Protected and Geothermal Crops in Chenchou; N/PL: Number of Nesidiocoris tenuis per plant; HAT: Hour after treatment; DAT: Day after treatment; $R^{2}$ : Coefficient of determination; $P$ : $P$ value

\section{Acknowledgements}

We thank Jaouad Mohamed, Medenine Economics and Rural Societies Laboratory, for the effort he put into reviewing the statistical analyses; Khatteli Houcine and Nagaz Kameleddine, Medenine Arid Land Institute, because of their interest in this work and the provision of all work requirements; and Ben Belgacem Ali and Belkadhi Mohamed Sadok for identification of native predator Nesidiocoris tenuis.

The plants used in this study were prepared at the technical center for protected and geothermal crops by sowing seeds of crops listed in the official catalog in the order of the Minister of Agriculture, Water Resources and Fisheries in Tunisia.

\section{Authors' contributions}

Conceptualization: BHA and MSB. Methodology: BHA and MSB. Formal analysis: BHA and SC. Investigation: BHA, SC, and RE. Resources: RE, NMB, and MSB. Data curation: BHA, SC, and RE. Writing —original draft preparation: BHA, SC, and RE. Writing - review and editing: BHA, NMB, and MSB. Visualization: BHA, SC, and MSB. Supervision: BHA, NMB, and MSB. Funding acquisition: BHA and MSB. All authors have read and agreed to the published version of the manuscript. 


\section{Funding}

This study was funded by two organizations: the Technical Center for Protected and Geothermal Crops provided the plants and the products tested while the Institute of Arid Regions has provided the analytical laboratory "Dryland and Oases Cropping Laboratory," the growth chambers under controlled conditions and will provide funding to pay the publication charges for this article.

Technical Center for Protected and Geothermal Crops:

Address: Technical Center for Protected and Geothermal Crops Street Abou

Elkacem Echabi El Manara P.B. 65, 6011, Gabes, Tunisia

URL website: http://ctcpg.com.tn/

Arid regions Institute

Address: Dryland and Oases Cropping Laboratory, Arid regions Institute,

Street El Jorf, 4119 Medenine, Tunisia

URL website: http://www.ira.agrinet.tn/

\section{Availability of data and materials}

All data of the study have been presented in the manuscript, and high quality and grade materials were used in this study.

\section{Declarations}

\section{Ethics approval and consent to participate}

Not applicable

\section{Consent for publication}

Not Applicable

\section{Competing interests}

The authors declare that they have no competing interests.

\section{Author details}

'Dryland and Oases Cropping Laboratory, Arid Regions Institute, Street El Jorf, 4119 Medenine, Tunisia. ${ }^{2}$ Phytopathology Laboratory, Higher Agronomic Institute, Chott Mariem, University of Sousse, B.P. 47, 4042 Chott, Mariem, Sousse, Tunisia.

\section{Received: 21 November 2020 Accepted: 23 February 2021}

Published online: 08 March 2021

\section{References}

Aggarwal N, Sharma S, Jalali SK (2016) On-farm impact of biocontrol technology against rice stem borer, Scircophaga incertulas (Walker) and rice leaf folder Cnaphalocrocis medinalis (Guenee) in aromatic rice. Entomologia Generalis 36: 137-148. https://doi. org/10.1127/entomologia/2016/0135

Bel Kadhi MS (2004) Etude bioécologique de Bemisia tabaci (Homoptera : Aleyrodidae) dans les serres géothermiques du sud tunisien. Possibilité de son contrôle biologique au moyen de parasitoïdes indigènes, Paul Cezanne Aix-Marseille

Ben Belgacem A, Ettaib R, Assadi B, Larayedh A, Belkadhi MS (2016) Maintien de Nesidiocoris tenuis durant la saison estivale. Revue des Régions Arides n43 (3) 2017) - Numéro spécial - Actes du 5ème Meeting International sur l'Aridoculture et les Cultures Oasiennes: Biotechnologie végétale en zones arides et oasiennes Zarzis (Tunisie)

Calvo FJ, Lorente MJ, Stansly PA, Belda JE (2012) Preplant release of Nesidiocoris tenuis and supplementary tactics for control of Tuta absoluta and Bemisa tabaci in greenhouse tomato. Entomologia Experimentalis et Applicata 143 111-119. https://doi.org/https://doi.org/10.1111/j.1570-7458.2012.01238.x

Calvo J, Bolckmans K, Stansly PA, Urbaneja A (2009) Predation by Nesidiocoris tenuis on Bemisia tabaci and injury to tomato. BioControl 54: 237-246. https:// doi.org/https://doi.org/10.1007/s10526-008-9164-y

Cuthbertson AGS, Blackburn LF, Northing P, Luo W, Cannon RJC, Walters KFA (2008) Further compatibility tests of the entomopathogenic fungus Lecanicillium muscarium with conventional insecticide products for control of sweetpotato whitefly, Bemisia tabaci on poinsettia plants. Insect Science 15: 355-360. https://doi.org/https://doi.org/10.1111/j.1744-7917.2008.00221.x

Cuthbertson AGS, Walters KFA, Northing P (2005) The susceptibility of immature stages of Bemisia tabaci to the entomopathogenic fungus Lecanicillium muscarium on tomato and verbena foliage. Mycopathologia 159:23-29
Faria M, Wraightb SP (2001) Biological control of Bemisia tabaci with fungi. Crop Protection 20: 767-778. https://doi.org/https://doi.org/10.1016/S0261-2194 (01)00110-7

Ghulam Ali B, Wang B, Cao N, Lin Hua F (2018) Pathogenicity of Beauveria bassiana strain 202 against sap-sucking insect pests. Plant Protection Science 54: 111-117. https://doi.org/https://doi.org/10.17221/45/2017-PPS

Henderson CF, Tilton EW (1955) Tests with acaricides against the brown wheat mite. J Econ Entomol 48:157-161

Keerio AU, Nazir T, Abdulle YA, Jatoi GH, Gadhi MA, Anwar T, Sokea T, Qiu D (2020) In vitro pathogenicity of the fungi Beauveria bassiana and Lecanicillium lecanii at different temperatures against the whitefly, Bemisia tabaci (Genn.) (Hemiptera: Aleyrodidae). Egypt J Biol Pest Control 30: 1-9. https://doi.org/https://doi.org/10.1186/s41938-020-00247-8

Malekan N, Hatami B, Akhavan A, Ebadi R, Radjabi R (2015) Evaluation of entomopathogenic fungi Beauveria bassiana and Lecanicillium muscarium on different nymphal stages of greenhouse whitefly Trialeurodes vaporariorum in greenhouse conditions. Biharean Biologist 9:108-112

Mascarin GM, Kobori NN, Quintela ED, Delalibera I (2013) The virulence of entomopathogenic fungi against Bemisia tabaci biotype B (Hemiptera: Aleyrodidae) and their conidial production using solid substrate fermentation. Biol Control 66: 209-218. https://doi.org/https://doi.org/10.1016/ j.biocontrol.2013.05.001

de Faria MR, Wraight SP (2007) Mycoinsecticides and mycoacaricides: a comprehensive list with worldwide coverage and international classification of formulation types. Biological Control 43: 237-256. https://doi.org/https:// doi.org/10.1016/j.biocontrol.2007.08.001

Oliveiraa MRV, Henneberryb TJ, Andersonc P (2001) History, current status, and collaborative research projects for Bemisia tabaci. Crop Prot 20: 709-723. https://doi.org/https://doi.org/10.1016/S0261-2194(01)00108-9

Park H, Kim K (2010) Selection of Lecanicillium Strain with high virulence against developmental stages of Bemisia tabaci. Mycobio/ 38: 210-214. https://doi.10. 4489/MYCO.2010.38.3.210

Perdikis D, Arvaniti K (2016) Nymphal development on plant vs. leaf with and without prey for two omnivorous predators: Nesidiocoris tenuis (Reuter, 1895)(Hemiptera: Miridae) and Dicyphus errans (Wolff, 1804)(Hemiptera: Miridae). Entomologia Generalis, 297-306. https://doi.10.1127/entomologia/ 2016/0219

Polanczyk RA, Gonçalves KC, Duarte RT, Silva IHSd, Espinosa DJL (2019) Potential of entomopathogenic fungi as biological control agents of whitefly (Bemisia tabaci biotype B) (Genn.) (Hemiptera: Aleyrodidae). Journal of Experimental Agriculture International, 1-8. https://doi.org/https://doi.org/10.9734/jeai/2019/ v38i630320

Polston JE, De Barro P, Boykin LM (2014) Transmission specificities of plant viruses with the newly identified species of the Bemisia tabaci species complex. Pest Manag Sci 70: 1547-1552. https://doi.org/https://doi.org/1 0.1002/ps.3738

Poprawski TJ, Greenberg SM, Ciomperlik MA (2000) Effect of host plant on Beauveria bassiana- and Paecilomyces fumosoroseus-induced mortality of Trialeurodes vaporariorum (Homoptera: Aleyrodidae). Environ Entomol 29 : 1048-1053. https://doi.org/https://doi.org/10.1603/0046-225X-29.5.1048

Quesada-Moraga E, Maranhao EAA, Valverde-García P, Santiago-Álvarez C (2006) Selection of Beauveria bassiana isolates for control of the whiteflies Bemisia tabaci and Trialeurodes vaporariorum on the basis of their virulence, thermal requirements, and toxicogenic activity. Biol Control 36: 274-287. https://doi. org/https://doi.org/10.1016/j.biocontrol.2005.09.022

Sain SK, Monga D, Kumar R, Nagrale DT, Hiremani NS, Kranthi S (2019) Compatibility of entomopathogenic fungi with insecticides and their efficacy for IPM of Bemisia tabaci in cotton. J Pestic Sci 44: 97-105. https://doi.org/ https://doi.org/10.1584/jpestics.D18-067

Sanchez JA, Lacasa A, Arnó J, Castañé C, Alomar O (2009) Life history parameters for Nesidiocoris tenuis (Reuter) (Het., Miridae) under different temperature regimes. J App/ Entomol 133: 125-132. https://doi.org/https://doi.org/10.1111/ j.1439-0418.2008.01342.x

Sanchez JA, La-Spina M, Lacasa A (2014) Numerical response of Nesidiocoris tenuis (Hemiptera: Miridae) preying on Tuta absoluta (Lepidoptera: Gelechiidae) in tomato crops. Eur J Entomol 111: 387-395. https://doi.org/https://doi.org/1 0.14411/eje.2014.041

Trdan S, Laznik Ž, Bohinc T (2020) Thirty years of research and professional work in the field of biological control (predators, parasitoids, entomopathogenic and parasitic nematodes) in Slovenia: a review. Applied Sciences, 10(21), 7468. https://doi.org/https://doi.org/10.3390/app10217468 
Urbaneja A, Tapia G, Stansly P (2005) Influence of host plant and prey availability on developmental time and surviorship of Nesidiocoris tenuis (Het.: Miridae). Biocontrol Sci Technol 15 (5): 513-518. https://doi.org/https://doi.org/10.1080/ 09583150500088777

Yano E, Nakauchi M, Watanabe T, Watanabe H, Hosaka S, Nishimori S, Miura S, Hinomoto N (2020) Life history traits of Nesidiocoris tenuis on Bemisia tabaci and Thrips palmi. BioControl, 65(2), 155-164. https://doi.org/https://doi.org/1 0.1007/s10526-019-09979-5

\section{Publisher's Note}

Springer Nature remains neutral with regard to jurisdictional claims in published maps and institutional affiliations.

\section{Submit your manuscript to a SpringerOpen ${ }^{\mathcal{O}}$ journal and benefit from:}

- Convenient online submission

- Rigorous peer review

- Open access: articles freely available online

High visibility within the field

- Retaining the copyright to your article

Submit your next manuscript at $\boldsymbol{\nabla}$ springeropen.com 